\title{
Erratum to: Bioremediation of Cd by Microbially Induced Calcite Precipitation
}

\author{
Chang-Ho Kang • Sang-Hyun Han • YuJin Shin • \\ Soo Ji Oh • Jae-Seong So
}

Published online: 29 April 2015

(C) Springer Science+Business Media New York 2015

\section{Erratum to: Appl Biochem Biotechnol (2014) 172:1929-1937 \\ DOI 10.1007/s12010-013-0626-Z}

\section{Appl Biochem Biotechnol (2014) 172:2907-2915 \\ DOI 10.1007/s12010-014-0737-1}

The Editor wishes to draw your attention to the inadvertent duplicate publication of "Bioremediation of Cd by Microbially Induced Calcite Precipitation" by Chang-Ho Kang, SangHyun Han, YuJin Shin, Soo Ji Oh, Jae-Seong So published in Applied Biochemistry and Biotechnology, Volume 172, Issue 4, pp 1929-1937 (February 2014). This article was also published in Applied Biochemistry and Biotechnology, Volume 172, Issue 6, pp 2907-2915 (March 2014) by the same authors.

The online version of the original article can be found at http://dx.doi.org/10.1007/s12010-013-0626-z and http:// dx.doi.org/10.1007/s12010-014-0737-1.

C.-H. Kang $\cdot$ S.-H. Han • Y. Shin $\cdot$ S. J. Oh · J.-S. So $(\bowtie)$

Department of Biological Engineering, Inha University, Yonghyun-dong, 253 Nam-gu, Incheon 402-751,

South Korea

e-mail: sjaeseon@inha.ac.kr 